\title{
Interprofessional knowledge and perceptions of selected South African healthcare practitioners towards each other
}

\author{
T J Ellapen, ${ }^{1} \mathrm{PhD}$; M Swanepoel, ${ }^{1} \mathrm{PhD} ; \mathbf{B}$ T Qumbu, ${ }^{1}$ BA Hons; G L Strydom, ${ }^{1} \mathrm{PhD} ;$ Y Paul, ${ }^{2} \mathrm{PhD}$ \\ ${ }^{1}$ PhASRec, Faculty of Health Sciences, North-West University, Potchefstroom campus, South Africa \\ ${ }^{2}$ Department of Sport, Rehabilitation and Dental Science, Faculty of Science, Tshwane University of Technology, South Africa
}

Corresponding author: TJ Ellapen (tellapen1@yahoo.com)

\begin{abstract}
Background. Interprofessional collaboration is internationally and popularly envisioned as a successful paradigm for the management of disease, disabilities and injuries. Despite this, the opinion of South African (SA) healthcare practitioners towards this idea is incoherent; this division of opinion needs to be changed to serve the common goal of better patient care.

Objective. To provide a narrative overview of literature-based evidence of interprofessional knowledge and perceptions of SA doctors, nurses, physiotherapists, occupational therapists, dieticians, speech and hearing therapists, as well as biokineticists regarding interprofessional collaboration.

Methods. An electronic search of Google Scholar, Crossref, PubMed and Sabinet databases identified 701 records, which were synthesised to 11 articles that were published during 2005 - 2016. Individual article quality was appraised using the modified Downs and Black scale.

Results. Of the 11 records, 3 were Master's theses reviewing the interprofessional knowledge and perceptions of doctors, physiotherapists and biokineticists towards the profession of chiropractic therapy; 3 examined the perceptions of chiropractic therapy, occupational therapy, speech and hearing therapy and biokinetics towards physiotherapy and chiropractic therapy; while the remaining 5 were supportive of interprofessional collaboration. The nature of the research designs of the selected studies were: survey $(n=6)$, short communication $(n=1)$, clinical commentary $(n=1)$, randomised controlled trial $(n=1)$ and focus group interview $(n=2)$. An incoherence underlies the perceptions of the abovementioned practitioners regarding interprofessional collaboration owing to lack of interprofessional knowledge regarding each given discipline's scope of profession (SoP). This is compounded by uneasiness with regard to patient competition. Some physiotherapists are against collaborative relationships, while occupational therapists, biokineticists and chiropractors are inclined to support the notion of a multidisciplinary physical rehabilitation team. There is a paucity of literature-based evidence reviewing the knowledge and perceptions of medical doctors, nurses and physiotherapists with regard to the SoP of occupational therapists, speech and hearing therapists, biokineticists, dieticians and chiropractors, thereby warranting future investigation.

Conclusions. There are mixed perceptions of interprofessional collaboration among the selected healthcare practitioners owing to negative perceptions.
\end{abstract}

Afr J Health Professions Educ 2018;10(3):148-152. DOI:10.7196/AJHPE.2018.v10i3.951

International academic and professional healthcare fraternities share a common vision of interprofessional collaboration among the medicine, nursing and social sciences, and rehabilitation and paramedical professions. ${ }^{[1]}$ Interprofessional collaboration among healthcare practitioners stems from interprofessional education. ${ }^{[1-3]}$ Reeves et al. ${ }^{[1]}$ state that interprofessional education occurs when medical, rehabilitative, nursing and social science professions study interactively for the primary purposes of improving interprofessional collaboration and enhancing the health and wellbeing of patients. Interprofessional education, research and collaboration among academics and practitioners break down the barriers of professional individualism, antagonism and competition, allowing a more holistic and multivalent approach to patient care - thereby responding to the needs of the patient in a more dynamic manner. ${ }^{[1]}$ Global advocacy for the adoption of interprofessional collaboration is based on the following validated claims: (i) respect for each other's profession; (ii) enhanced patient management; (iii) optimal use of each healthcare team member's skills; and (iv) provision of better healthcare to patients. ${ }^{[1]}$ Interprofessional collaboration has been shown to enhance patient wellbeing and reduce the medical expense of noncommunicable diseases (NCDs) and orthopaedic injuries. ${ }^{[3]}$ Unfortunately, not all medical, rehabilitative, nursing and social science practitioners support interprofessional collaboration..$^{[4-6]}$
The opposite of interprofessional collaboration is professional individualism, which leads to antagonism and competition, with both national and international concerns being frequently brought to the surface regarding an individual discipline's scope of profession (SoP) and the issue of SoP trespassing among various medical, social science and rehabilitation practitioners, thereby inhibiting the progress of interprofessional healthcare collaboration. ${ }^{[1]}$ South Africa (SA) has a long history of professional individualism and opposition to interprofessional collaboration among healthcare practitioners. ${ }^{[4-6]}$ Naidoo and Buhler, ${ }^{[4]}$ as well as Keyter, ${ }^{[5]}$ reported that the alleged trespassing of the chiropractic profession on the SoP of physiotherapy and occupational therapy resulted in chiropractic therapy's deregistration from the Health Professions Council of South Africa (HPCSA). Recently, allegations regarding the profession of biokinetics, accused of trespassing onto the SoP of physiotherapy, have adversely affected the former. ${ }^{[6]}$ Professional individualism and separation have an adverse effect on the quality of available healthcare. ${ }^{[3]}$ The lack of interprofessional knowledge regarding healthcare leads to incorrect perceptions and professional individualism, which result in a dearth of patient referrals to applicable healthcare practitioners. ${ }^{[4,5]}$ However, there is still hope that the SA healthcare fraternity will adopt the concept of interprofessional collaboration. Felsher and Ross ${ }^{[7}$ 
reported that interdisciplinary collaboration among SA physiotherapists, occupational therapists and speech and hearing therapists is important during the rehabilitation of stroke patients. According to Booysen et al. ${ }^{[8]}$ however, despite the encouragement of interprofessional knowledge and collaboration among SA dietetic, occupational therapy, physiotherapy and medical students at tertiary educational institutions, this does not carry over into practice, adversely affecting the quality of SA healthcare. Nonetheless, the idea of interprofessional collaboration among SA healthcare practitioners has existed for $\sim 100$ years.

The earliest recorded idea regarding the development of an SA multidisciplinary medical rehabilitation team can be traced to 1920 , when a medical report surfaced identifying the poor fitness condition of young SA men who wanted to join the military. ${ }^{[9-11]}$ In 1934, this culminated in the establishment of the Physical Training Brigade, a specialised unit of the SA National Defence Force aimed at rehabilitating boys with various medical and psychological illnesses, musculoskeletal injuries and disabilities. ${ }^{[1]}$ This multidisciplinary medical rehabilitation team included physical education instructors, medical doctors, dentists, psychologists, physiotherapists, occupational therapists and social scientists.

SA is experiencing an upsurge in the incidence of NCDs, which is further increased by inept knowledge of prudent interprofessional healthcare. ${ }^{[12]}$ NCDs are non-infectious, non-transferable chronic diseases, which inter alia include cancer, diabetes mellitus and cardiorespiratory diseases. ${ }^{[12]}$ The SA national healthcare plan should consider the strategy of a multidisciplinary medical rehabilitation team to manage, educate and prevent NCDs and orthopaedic injuries. Such strategies have been adopted internationally, earning great success. ${ }^{[3,13,14]}$ Collaborative interaction within a multidisciplinary medical rehabilitation team has been identified as the most effective method of delivering quality healthcare. ${ }^{[13,14]}$ International healthcare trends show a decrease in the number of general hospitals and an increase in multidisciplinary hospitals (encouraging interprofessional co-operation) ${ }^{[13,14]}$ This effort has led to shorter inpatient hospital stays and consequently decreased medical costs, while improving healthcare. . $^{[3,13,14]}$

The success of these international multidisciplinary medical rehabilitation teams is dependent on the positive perceptions of their individual practitioners towards each other, as influenced by their interprofessional knowledge regarding each practitioner's SoP. ${ }^{[1-3,13,14]}$ Where knowledge is the mindfulness or comprehension of a person, profession or function learnt through discovery and/or education, ${ }^{[15]}$ perception is the manner an individual thinks or understands another person, function or profession with/without knowledge. ${ }^{[15]}$ The positive perceptions shared by these international practitioners are developed during their formal academic training through interprofessional education regarding the specific SoP of each discipline. ${ }^{[2,3,13,14]}$ Three Cochrane systematic reviews pertaining to interprofessional collaboration among international healthcare practitioners have been published, indicating the importance of this global concept ${ }^{[1]}$ their findings were supportive of interprofessional global healthcare collaboration. ${ }^{[1]}$ There has, however, been no narrative overview of the status of SA healthcare practitioners' knowledge and perceptions regarding the concept of interprofessional collaboration. The objective of this article is to provide a narrative overview of the literature evidence of interprofessional knowledge and perceptions shared by SA doctors, nurses, occupational therapists, physiotherapists, speech and hearing therapists, biokineticists and dieticians.

\section{Methods}

The authors followed the standard practices for systematic reviews, known as preferred reporting items for systematic reviews and meta-analyses (PRISMA). The definitions were guided by the PRISMA checklist for participants, interventions, comparisons, outcomes and study designs (PICOS).

\section{Information sources and searches}

A literature search of peer-reviewed, accredited journal publications and records was conducted in the following search engines: Crossref Metadata base, an academic metadata base comprised of PubMed, MEDLINE, ScienceDirect, EBSCOhost, CINAHL, Sabinet and Google Scholar search engines (Fig. 1). The keywords used were 'knowledge', 'perceptions', 'medical doctors', 'nurses', 'physiotherapists', 'chiropractors', 'occupational therapists', 'speech and hearing therapist', 'dieticians' and 'biokineticists. The screening eligibility of articles was performed in the following three steps: (i) title screen; (ii) abstract screen; and (iii) full text screen. The articles were screened by TJE, BTQ, MS and GLS.

\section{Eligibility criteria}

The participants in this study reflected the interprofessional knowledge and perceptions within the SA medical rehabilitation community; the intervention was not necessarily a therapeutic one, but was interpreted as an exposure, i.e. the knowledge and perceptions of selected SA medical rehabilitation practitioners towards each other. The outcomes of interest were: (i) interprofessional knowledge among selected SA medical rehabilitation practitioners; and (ii) interprofessional perceptions of selected SA medical rehabilitation practitioners towards each other. The exclusion

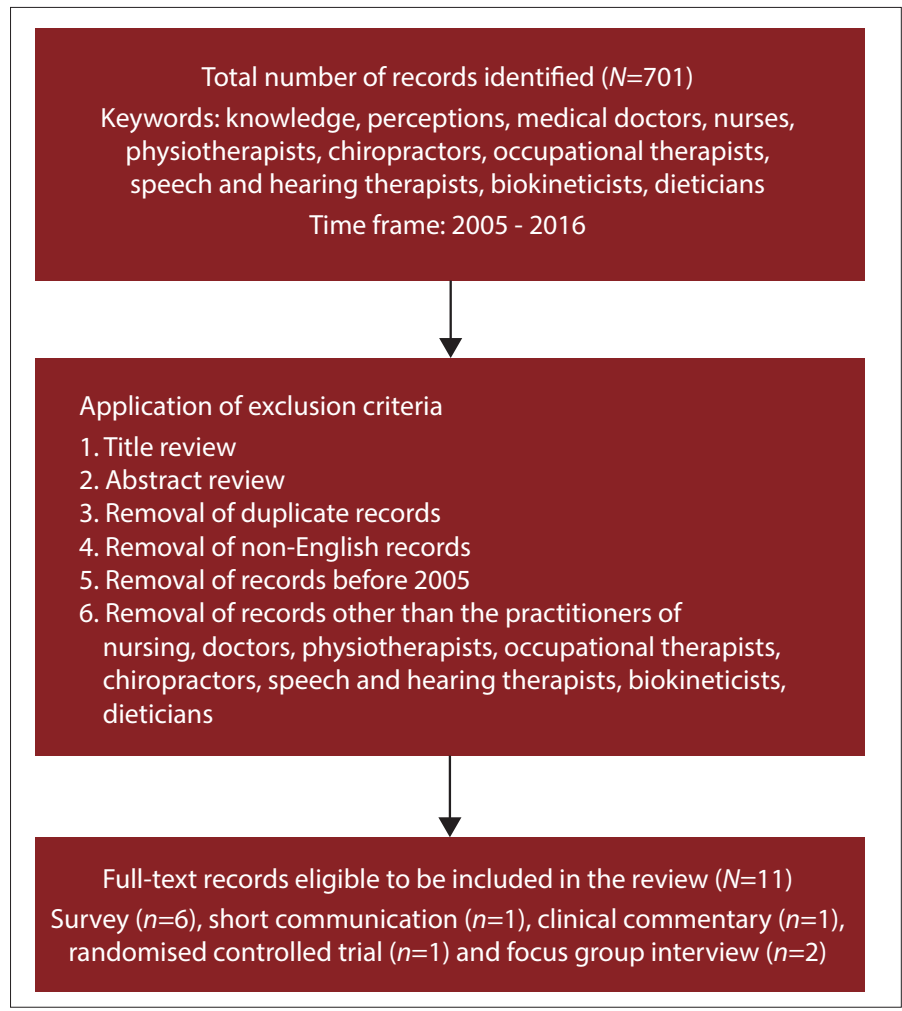

Fig. 1. Conceptualisation of the review process. 
criteria were: (i) publications before 2005; (ii) non-English articles; (iii) interprofessional knowledge and perceptions of SA medical rehabilitation practitioners other than those in the abovementioned list; and (iv) nonpeer-reviewed articles.

\section{Study selection: Appraisal of evidence and quality of studies}

The hierarchy of evidence was appraised by the tool adopted from Abdullah et al. ${ }^{[16]}$ (Table 1). All publications were filtered, based on the appropriateness of the title and whether they met the inclusion criteria. The authors included all levels of evidence owing to the limited literature available, provided the publications met the inclusion criteria.

The quality of individual articles was analysed by adopting the modified Downs and Black appraisal scale, which examines the quality of randomised controlled trials and non-randomised articles. ${ }^{[17]}$ The Downs and Black checklist was modified because not all items on the original checklist related to this article; the modified checklist consisted of 12 questions with a maximum of 12 points. Answers were scored as either 0 (no) or 1 (yes). The questions adopted were $1,2,3,6,10,11,12$, $13,15,18,20$ and 27, and these assessed each study's reporting prowess $(n=5)$, external validity $(n=3)$, internal validity $(n=3)$ and power of significance $(n=1)$ (Table 2). The sum of these scores was then expressed as a percentage of the overall estimation of the quality of the article, where the overall quality was graded as: $<50 \%$ (weak), $50-69 \%$ (fair), 70 - $79 \%$ (good) and $\geq 80 \%$ (very good), as per the grading criteria adopted by Li et al. ${ }^{[18]}$ Table 1 describes the appraisal methods and characteristics of each study.

\section{Results}

The electronic literature survey identified 701 records, which were reduced to 11 publications after stringent application of exclusion criteria (Fig. 1). Table 1 apprises the hierarchy of the records as per the guidelines laid out by Abdullah et al., ${ }^{[16]}$ describing the type of research design adopted by the respective authors. Table 2 evaluates each study according to the modified Downs and Black appraisal scale. ${ }^{[17]}$ A descriptive overview of the characteristics and findings of the studies is given in Table 3. Of the 11 records, 3 were Master's theses reviewing the interprofessional knowledge and perceptions of doctors, physiotherapists and biokineticists towards the profession of chiropractic therapy; 3 examined the perceptions of chiropractic therapy, occupational therapy, speech and hearing therapy and biokinetics towards physiotherapy and chiropractic therapy; while the remaining 5 were supportive of interprofessional collaboration.

There were 1053 participants across the 11 studies, with sample sizes varying from 8 to 449 . The professions involved were medicine, nursing science, physiotherapy, occupational therapy, dietetics, biokinetics and speech and hearing therapy. The nature of the research designs of the selected studies were: survey $(n=6)$, short communication $(n=1)$, clinical commentary $(n=1)$, randomised controlled trial $(n=1)$ and focus group interview $(n=2)$. The overall quality of the studies rated as very good (80\%) (Table 2$)$.

Records are arranged chronologically and then alphabetically.

\section{Discussion}

The discussion presents the status of the abovementioned SA healthcare practitioners towards interprofessional collaboration, as well as current

Table 1. Appraisal of the hierarchy of records as per Abdullah et al. ${ }^{[16]}$

\begin{tabular}{llll}
\hline Level & Record type & Record, $n$ & Authors \\
\hline I & Systematic review & 0 & None \\
II-1 & Randomised controlled trial & 0 & None \\
III-1 & Pseudo-randomised controlled trial & 0 & None \\
III-2 & Comparative study with concurrent controls & 3 & Naidoo and Buhler $(2009),{ }^{[4]}$ Booysen et al. $(2012),{ }^{[8]}$ Chetty et al. $\left.(2014)\right)^{[26]}$ \\
III-3 & Comparative study without concurrent controls & 8 & Louw $(2005),{ }^{[20]}$ Naidoo $(2008),{ }^{[21]}$ Keyter $(2010),{ }^{[5]}$ Puckree et al. $(2011),{ }^{[22]}$ \\
& & & Van Staden et al. $(2011),{ }^{[19]}$ Ellapen et al. $(2016),{ }^{[25]}$ Manillal and Rowe \\
& & & $(2016),{ }^{[24]}$ Rowe $(2016){ }^{[23]}$ \\
IV & Case series/studies with either post-test or pretest/ & 0 & None \\
& post-test outcomes & &
\end{tabular}

Table 2. Appraisal of records according to the modified Downs and Black appraisal scale ${ }^{[17]}$

\begin{tabular}{|c|c|c|c|c|c|c|}
\hline \multirow[b]{2}{*}{ Authors } & \multicolumn{6}{|c|}{ Downs and Black appraisal scale } \\
\hline & Reported $(n=5)$ & $\begin{array}{l}\text { External validity } \\
(n=3)\end{array}$ & $\begin{array}{l}\text { Internal validity } \\
(n=3)\end{array}$ & Power $(n=1)$ & Total $(N=12)$ & $\begin{array}{l}\text { Grading } \\
\%=x / 12 \times 100\end{array}$ \\
\hline Louw $(2005)^{[20]}$ & 5 & 3 & 2 & 1 & 11 & 91.6 \\
\hline Naidoo $(2008)^{[21]}$ & 5 & 3 & 2 & 1 & 11 & 91.6 \\
\hline Naidoo and Buhler (2009) $)^{[4]}$ & 5 & 3 & 2 & 1 & 11 & 91.6 \\
\hline Keyter $(2010)^{[5]}$ & 5 & 3 & 2 & 1 & 11 & 91.6 \\
\hline Puckree et al. $(2011)^{[22]}$ & 5 & 3 & 2 & 1 & 11 & 91.6 \\
\hline Van Staden et al. $(2011)^{[19]}$ & 5 & 3 & 3 & 3 & 12 & 100 \\
\hline Booysen et al. $(2012)^{[8]}$ & 5 & 2 & 2 & 1 & 10 & 83.3 \\
\hline Chetty et al. $(2014)^{[26]}$ & 4 & 3 & 2 & 1 & 10 & 83.3 \\
\hline Ellapen et al. $(2016)^{[25]}$ & 4 & 1 & 0 & 1 & 6 & 50.0 \\
\hline Manillal and Rowe (2016) ${ }^{[24]}$ & 4 & 3 & 2 & 1 & 10 & 83.3 \\
\hline Rowe $(2016)^{[23]}$ & 2 & 0 & 0 & 1 & 3 & 25.0 \\
\hline
\end{tabular}




\section{Research}

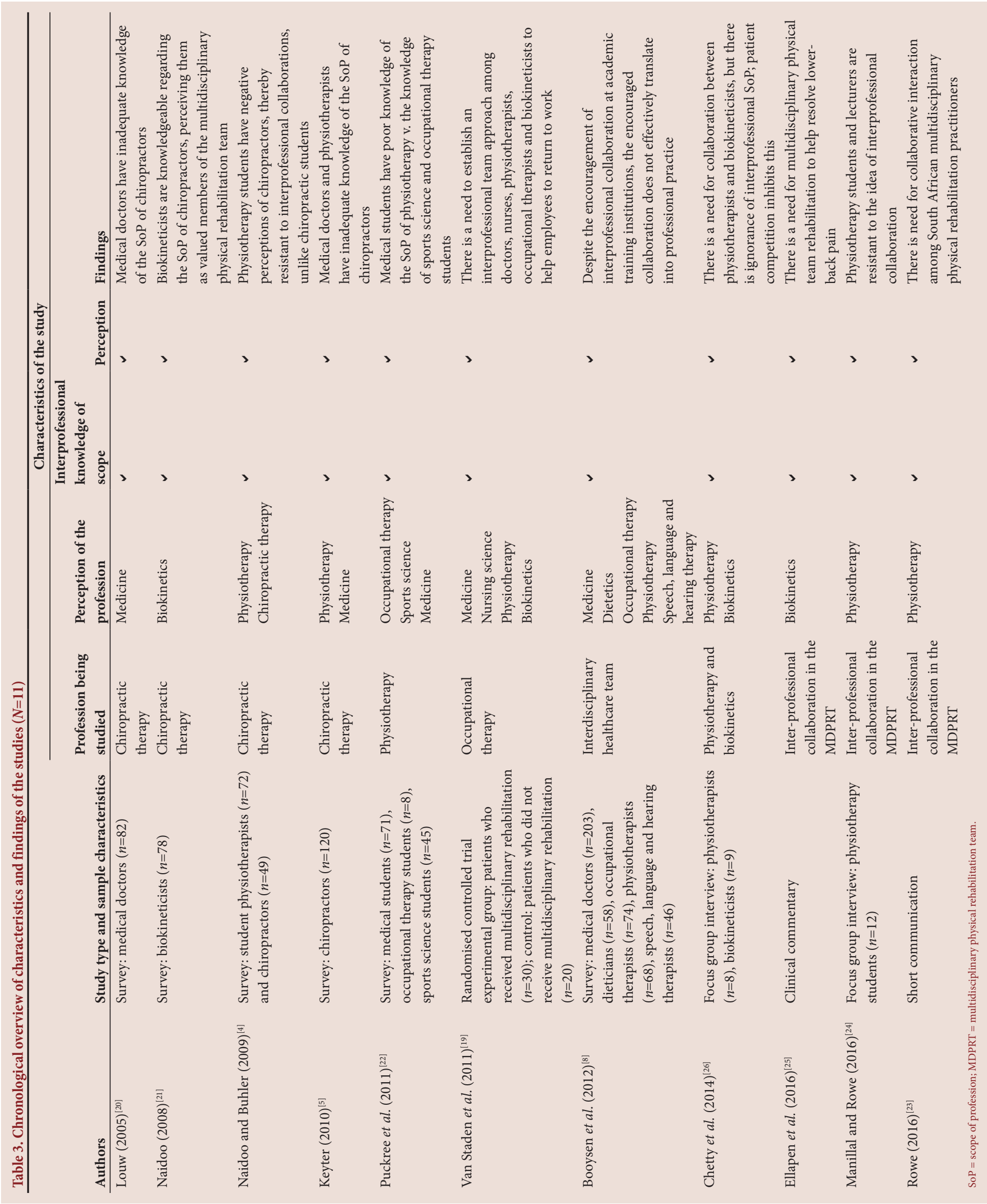


plausible solutions to counter the resistance to interprofessional collaboration

The initial findings identified the visible paucity of literature-based evidence regarding interprofessional SoP knowledge, perceptions and collaboration among SA healthcare practitioners, which warrants further research. The literature-based evidence presents a disjointed consensus towards the formulation of an SA multidisciplinary medical rehabilitation team. The disjointed nature of the consensus is primarily due to a lack of interprofessional knowledge, which is coupled with certain negative perceptions among the various abovementioned disciplines. ${ }^{[5,20-22]}$ The profession of physiotherapy is generally negative towards the establishment of collaborative relationships with chiropractors and biokineticists owing to their perception that these professionals are trespassing on their SoP and pilfering their patients. ${ }^{[2,24]}$ Medical doctors and students are not generally mindful and appreciative of the individual SoP of physiotherapists and chiropractors; this has produced animosity between these professions, thereby creating obstacles to the formulation of a multidisciplinary medical rehabilitation team. ${ }^{[22,24]}$ Chiropractors, speech and hearing therapists, dieticians, biokineticists and occupational therapists are favourably inclined to interprofessional collaboration owing to their sound interprofessional knowledge of each other's SoP. ${ }^{[4,8,19,21]}$ The literature presents no evidence of the interprofessional knowledge and perceptions that medical doctors, nurses and physiotherapists may have regarding biokineticists and occupational therapists. This gap in the literature requires future investigation.

One solution to the resistance expressed regarding interprofessional collaboration is the persistent encouragement and institutionalisation of tertiary interprofessional education among all healthcare students. ${ }^{[1,8,23,24]}$ International healthcare academic fraternities have integrated interprofessional healthcare education into their teaching curriculum, which has translated into interprofessional collaboration. ${ }^{[1-3,13,14]}$ There is literaturebased evidence that interprofessional healthcare collaboration provides the best level of healthcare, which should encourage SA healthcare practitioners to put aside their differences to collaboratively strive for improvement of healthcare. ${ }^{[13,14]}$ It is recommended that the HPCSA - the national statutory body for healthcare - institute quarterly roadshows and workshops to encourage interprofessional healthcare collaboration among all healthcare professions and practitioners. It is further recommended that the HPCSA prescribe a multidisciplinary medical rehabilitation team, including all healthcare practitioners, to manage, educate and prevent injuries, illnesses and disabilities among the SA population. This team should form part of the SA national healthcare plan to combat disease, disabilities and injuries. It is postulated that the abovementioned recommendations may encourage collaborative relationships among SA healthcare professionals.

\section{Conclusions}

A diverse range of perceptions regarding interprofessional healthcare collaboration exists owing in no small part to a lack of interprofessional knowledge of the individual SoP across the various medical and healthcare disciplines. The institutionalisation of interprofessional healthcare education among all relevant universities and colleges, as well as the persistent encouragement from the HPCSA, supporting interprofessional co-operation, should be undertaken to create a collaborative environment that will improve healthcare outcomes for patients.

\section{Acknowledgements. None.}

Author contributions. TJE: conceptualisation of the idea, screening of records, drafting and revision of manuscript; BTQ: screening of records, drafting of manuscript; MS: screening of records, drafting of manuscript; GLS: screening of records, drafting and revision of manuscript; and YP: drafting of manuscript.

Funding. None.

Conflicts of interest. None.

1. Reeves S, Perrier L, Goldman J, Freeth D, Zwarenstein M. Interprofessional education: Effects on professional practise and healthcare outcomes. Cochrane Database Syst Rev 2013;(3):CD002213. https://doi. org/10.1002/14651858.CD002213.pub3

2. Bridges DR, Davidson RA, Odegard SP, Maki IV, Tomkowiak J. Interprofessional collaboration: Three best

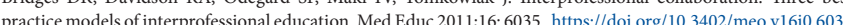
PcPhe $\mathrm{K}$, we aron K, Hello

and chiropractic students regarding each other's professional practise. S Afr J Physiother 2009;65(2):32-38. https://doi.org/10.4102/sajp v65i2.8

5. Keyter K. The perceptions of the South African chiropractors regarding their professional identity. MTech thesis. Durban: Durban University of Technology, 2010

6. Nhlapho S. Advisory letter to the stakeholders. Health Professions Council of South Africa, Pretoria. 2016. http:// www.hpcsa.ac.za (accessed 26 July 2016).

7. Felsher L, Ross E. The knowledge and attitudes of occupational therapy, physiotherapy and speech language therapy students regarding the speech language therapist's role in the hospital stroke rehabilitation team. S Afr Commun Disord 1994;41:49-56.

8. Booysen N, Lake J, Webb J, van Niekerk W, Schubl C. The knowledge, attitudes and perceptions of healthcare students and professionals regarding the interdisciplinary health worker team at Stellenbosch University and Tygerberg Academic Hospital. S Afr J Clin Nutr 2012;25(4):192-196. https://doi.org/10.1080/16070658.2012.1 Tygerberg

9. Geyer GJ. Liggaamlike opleiding in die Unie-Verdedigingsmag (1912 - 1946). MA thesis. Pretoria: University of Pretoria, 1969 .

10. Cilliers JJ. Die bydrae van geprogrammeerde inoefening in na-mediese fisieke rehabilitasie van beseerdes uit die miltêre operasionele gebied. PhD thesis. Potchefstroom: Potchefstroom University for Christian Higher die miltêre operas 1. Malan DDJ, Strydom GL. The evolution of physical education at the North-West University - a multifaceted
historical development. Afr J Phys Health Educ Recreat Dance 2007;(Suppl):1-22.

12. National Planning Commission. National Development Plan: Promoting Health. 2017. http://www. nationalplanningcommission.org.za (accessed 4 August 2017).

13. Vincent-Onabajo GO, Mustapha A, Oyeyemi AY. Medical students' awareness of the role of physiotherapy in multi-disciplinary healthcare. Physiother Theory Pract 2014;30(5):338-344. https://doi.org/10.3109/09593985.2 013.871765

14. Momsen A, Rasmussen JO, Nielsen CU, Iversen MD, Lund H. Multi-disciplinary team care in rehabilitation: An overview of reviews. J Rehab Med 2012;44:901-912. https://doi.org/10.2340/16501977-1040

15. Stevenson A, Lindberg CA. New Oxford American Dictionary. 3rd ed. Oxford: Oxford University Press, 2010.

16. Abdullah AM, McDonald R, Jaberzadeh S. The effects of backpack load and placement on postural deviation in healthy students: A systematic review. Int J Engineer Res Appl 2012;2(6):466-481.

17. Downs SH, Black N. The feasibility of creating a checklist for the assessment of the methodological quality both of randomized and non-randomized studies of health care interventions. J Epidemil Commun Health both of randomized and non-randomized studies of heath

18. Li C, Khoo S, Adnan A. Effects of aquatic exercise on physical function and fitness among people with spinal cord injury: A systematic review. Medicine 2017;96(11):e6328. https://doi.org/10.1097/md.0000000000006328

9. Van Staden H, Kemp R, Beukes S. Return to work of patients after lumbar surgery. S Afr J Occup Ther 2011;41(3):1-9.

20. Louw ID. The knowledge of general practitioners about chiropractics as a factor that may influence health care integration in South Africa. MTech thesis. Durban: Durban Institute of Technology, 2005.

21. Naidoo M. A survey to determine the knowledge and perceptions of biokineticists with respect to the chiropractic profession. MTech thesis. Durban: Durban Institute of Technology, 2008.

22. Puckree T, Harinarain R, Ramdath R, Singh RB, Ras J. Knowledge, perceptions and attitudes of final year medical, occupational therapy and sports science students regarding physiotherapy, in KwaZulu Natal. S Afr J Physiother 2011;67(3):19-26. https:///oi.org/10.4102/saj.v67i3.50

23. Rowe M. The future of education in complex systems. Afr J Health Professions Educ 2016;8(2):128. https://doi. org M. M196/

24. Manillal J, Rowe M. Collaborative competency in physiotherapy students: Implications for interprofessional education. Afr J Health Professions Educ 2016;8(2):217-221. https://doi.org/10.7196/ajhpe.2016.v8i2.841

25. Ellapen TJ, Swanepoel M, Strydom GL. A comparative review of the rehabilitative professions assisting patients with lower back pain in South Africa. S Afr J Res Sport, Phys Educ Recreat 2016;39(3):1-14.

26. Chetty V, Dunpath T, Bhagwandin R, et al. Collaboration between physiotherapists and biokineticists in managing low back pain in an urban setting in South Africa. Afr J Phys Health Educ Recreat Dance 2014;20(4.2):1587-1597. 